\title{
Myoelectrical activity of the Billroth II gastric
}

\section{remnant}

\author{
H M Schaap, A J P M Smout, L M A Akkermans
}

\begin{abstract}
This study was undertaken to investigate the extent to which gastric electrical control activity and phasic contractile activity are preserved after Billroth II resection and to assess the relation between these activities and postprandial symptoms in patients who have undergone Billroth II resection. Thirty three patients were studied after Billroth II resection without vagotomy. Gastric electrical activity was recorded from surface electrodes and intraluminal pressure was recorded simultaneously. The electrogastrographic signals were analysed by Running Spectrum Analysis. In addition, three dogs with a Billroth II stomach and implanted serosal electrodes were studied. Phasic gastric pressure waves were observed in most patients. Electrogastrographic signals recorded from $82 \%$ of the Billroth II patients contained a mean (SD) peak at $3.1(0.2)$ cycles per minute (cpm). Fasting and postprandial frequencies correlated significantly $(p<0.02)$ with the score for nausea and vomiting. In $61 \%$ of the patients, the electrogastrographic signal contained a stable component with a frequency of 10.5 $(0.6) \mathrm{cpm}$ that was not caused by respiration. We suggest that this activity is of intestinal origin. In all three dogs studied, retrograde conduction of jejunal electrical control activity (16 cpm) into the distal part of the gastric remnant was observed. In the Billroth II patients, the presence of a $10 \mathrm{cpm}$ component correlated negatively with symptoms.
\end{abstract}

Phasic contractions in the intact distal stomach are controlled, among other mechanisms, by a myoelectrical phenomenon which consists of rhythmically occurring transmembrane potential variations.' This electrical activity can also be recorded with extracellular electrodes as a regular, periodic signal. In man the frequency is approximately three cycles per minute (cpm). These so-called slow waves or electrical control activity $^{2}$ are always present and are independent of the presence of motor activity. Phasic contractions are related to a different type of electrical activity, characterised by spikes during a negative deflection occurring after the primary potential. This activity is called electrical response activity. ${ }^{3}$ No regular slow waves are present in the gastric fundus. The origin of this activity - that is the pacemaker - is found on the greater curvature, approximately in the proximal corpus, ${ }^{+}$from where the slow waves are propagated aborally, ${ }^{5}$ increasing in both amplitude and frequency. ${ }^{6}$

The Billroth II partial gastrectomy, one of the most commonly performed stomach resections, is well known for the frequency of postoperative symptoms like dumping, nausea, vomiting, and fullness. ${ }^{7}$ It has been shown that gastric emptying of both solids and semi-solids is disturbed after this surgical procedure ${ }^{8-10}$ and that the emptying characteristics are related to several of these symptoms." Smout et al have shown that gastric emptying studies in patients with a Billroth II gastric remnant are clinically relevant to their symptoms. ${ }^{11}$ Electrical and motor activities of the gastric remnant after a Billroth II resection are likely to be influenced by what happens to the pacemaker area and thus to the myoelectrical control mechanisms during and after surgery. ${ }^{12}$

This study was undertaken to investigate the extent to which gastric electrical control activity and phasic contractile activity are preserved after Billroth II resection and to assess any relation between these activities and postprandial symptoms in patients with a Billroth II gastric remnant.

\section{Material and methods}

We wrote to 230 patients who had undergone a Billroth II partial gastrectomy in our hospital between 1970 and 1986. Ninety of the 230 patients responded and 33 of these (six women, 27 men) were studied after informed consent had been obtained. In all 33 patients complicated peptic ulcer disease had been the indication for surgery - that is pyloric stenosis, history of perforation, bleeding, or medical intractability. All 33 patients had undergone a Billroth II resection without vagotomy (HofmeisterFinsterer type gastrojejunostomy) at least 10 months previously. The mean (SD) interval between surgery and the studies was $6 \cdot 2(5 \cdot 2)$ years (range $0 \cdot 8-15$ years). The patients' ages ranged from 20 to 80 years (mean (SD) 53 (14) years).

The operations had been performed by four different surgeons. All adhered to the same technique in performing a two third distal gastrectomy. The level of resection was determined by the relatively avascular plane between the left and right gastro-epiploic artery at the greater curvature and the division of the left gastric artery in its descending and ascending branch at the lesser curvature. ${ }^{13}$

All patients were interviewed by the same investigator, who was unaware of the outcome of any test. The frequency and intensity of 11 postprandial symptoms (fullness, nausea, vomiting, early dumping, late dumping, cramping pain, non-cramping pain, anorexia, regurgitation, heartburn, and diarrhoea) were scored separately, ranging from 0 (absent) to 3 . The final score for each symptom was made up by 
TABLE I Scores for various postprandial symptoms in patients who underwent a Billroth II gastric resection

\begin{tabular}{lll}
\hline & No of patients & Mean $(S D)$ score \\
\hline Fullness & 25 & $2 \cdot 64(1.94)$ \\
Nausea & 12 & $1 \cdot 27(1.88)$ \\
Vomiting & 10 & $0.79(1.46)$ \\
Early dumping & 5 & $0.61(1.54)$ \\
Late dumping & 3 & $0 \cdot 27(0.96)$ \\
Cramping pain & 8 & $0.97(1.78)$ \\
Non-cramping pain & 3 & $0.24(0.78)$ \\
Anorexia & 3 & $0.30(1.11)$ \\
Regurgitation & 14 & $1.33(1.63)$ \\
Heartburn & 10 & $0 \cdot 82(1.36)$ \\
Diarrhoea & 6 & $0.79(1.74)$ \\
\hline
\end{tabular}

adding the values for frequency and intensity. The general wellbeing of the patient was scored according to Visick. ${ }^{15}$ Interview and recording of intragastric pressures and electrical activity (as described below) took place on the same day.

Intragastric pressures were recorded by means of tube mounted miniature pressure transducers (Gaeltec, Dunvegan, Great Britain), with transducers placed 5,10 , and $15 \mathrm{~cm}$ from the distal tip respectively. The catheter was positioned with the proximal transducer just distally to the lower oesophageal sphincter.

Gastric electrical activity (electrogastrography) was recorded simultaneously from surface (skin) electrodes. ${ }^{36-18}$ Three unipolar, pregelled $\mathrm{Ag} / \mathrm{AgCl}$ (EKG) electrodes were positioned on a transverse line halfway between the lower end of the sternum and the umbilicus one at the intersection of this line and the median plane and the other two on either side of the first. The distance between the individual electrodes was $6 \mathrm{~cm}$.

The electrogastrographic signals were amplified by a differential amplifier (amplifying 5000 times), using high pass and low pass filters with cut off frequencies of 0.01 and $0.5 \mathrm{~Hz}$ respectively. Respiration was monitored using a temperature sensitive probe positioned at a nostril. All signals were recorded on a six channel Gould paper writer (paper speed $25 \mathrm{~mm} /$ minute) as well as on magnetic tape (seven channel Racal tape recorder, tape speed 15/16 in/second). Recording took place during fasting and after a semi-solid test meal consisting of $200 \mathrm{ml}$ of yoghurt to which $10 \mathrm{~g}$ of sugar had been added. The total recording time was at least one hour. The fasting and postprandial recording times were 30 to 50 minutes each.

The pressure signals recorded on the chart were analysed by measuring maximum and mean pressures and by calculating the incidence and fundamental frequency of the contraction waves A weak 3 present in the EGG signal. EGG

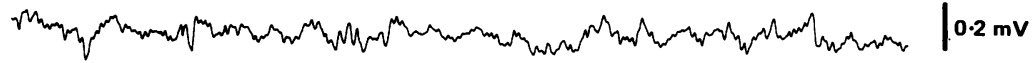

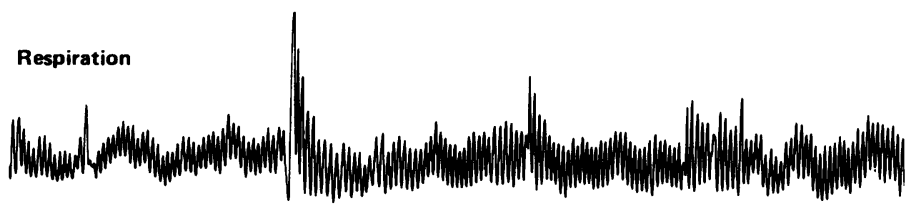

Pressure

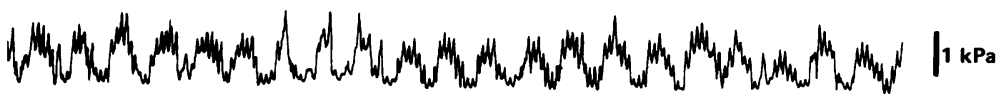

by counting the number of contractions per unit of time (stretches of four minutes) for both fasting and postprandial periods.

The electrogastrographic signals were analysed by Running Spectrum Analysis, ${ }^{17} 19$ a modification of Fast Fourier Transform in which a spectral frequency analysis is carried out on overlapping stretches of signal. This was performed by replaying the signal from tape at a speed that was 64 times the recording speed, using additional band pass filtering by means of Krohn-Hite 3322 filters $(24 \mathrm{~dB} /$ oct at high pass and low pass filters for 0.01 and $0.5 \mathrm{~Hz}$, respectively). After analogue to digital conversion (real time sample frequency $1 \mathrm{~Hz}$ ) stretches of 240 seconds overlapping for $75 \%$ were subjected to Fast Fourier Transform (using a programme written in Basic and a Hewlett-Packard computer). The frequency spacing was $0 \cdot 25 / 60 \mathrm{~Hz}$ $(0.25 \mathrm{cpm})$. Amplitudes (powers) were represented by means of 64 different grey levels for each point in the frequency time plane; thus a grey plot of the running spectra was formed with frequency on the $x$-axis, time on the $y$-axis, and power on the z-axis. ${ }^{19}$

In addition to the study in humans, three dogs (Beagles) were operated on to study the effect of Billroth II partial gastrectomy on the myoelectrical activity of the gastric remnant, and more specifically to look at the possible occurrence of retrograde propagation of jejunal electrical activity. A Billroth II gastric resection was performed followed by the implantation of four bipolar serosal $\mathrm{Ag} / \mathrm{AgCl}$ needle electrodes. Two electrodes were sutured on the distal part of the gastric remnant, one on the afferent jejunum and one on the efferent jejunum. All leads were tunnelled subcutaneously and soldered to a connector cemented on the dog's scalp, thus allowing repeated recording in the conscious animal. Recordings started two weeks after implantation and were continued for three to six months; recordings took place during fasting and after a test meal of normal dog food.

All data are expressed as mean (SD) unless otherwise stated. Statistical analysis of differences between groups was performed with Wilcoxon's rank test. Correlations between variables were assessed by calculation of Spearman's rank correlation coefficients.

\section{Results}

A considerable number of patients suffered from at least some degree of postprandial symptoms. Eight patients (24\%) could be classified as Visick I, 11 as Visick II (34\%), and five (15\%) and nine (27\%) patients had to be classified as Visick III and IV respectively. Postprandial fullness, nausea, vomiting, regurgitation, and cramping pain were particularly troublesome, but heartburn was also a prominent symptom in $30 \%$ of the patients (Table I).

Manometrically, the Billroth II gastric remnants showed phasic activity in all but one patient - that is, in $97 \%$ (Fig 1). The mean (SD) fundamental repetition frequency was $2 \cdot 8(0 \cdot 2)$ cpm (range $2 \cdot 4-3 \cdot 0$ ), both during fasting and postprandially. During fasting, contractions were present for $82(29) \%$ of the recording time. 
Figure 2: Running Spectrum Analysis of

electrogastrographic (EGG) recording from a patient with a Billroth II gastric

remnant, showing a low

frequency component at 3

cycles per minute (cpm), as

well as a high frequency

component at $10 \mathrm{cpm}$ (left panel).

Right panel: Running Spectrum Analysis

performed on a recording of respiration. The $10 \mathrm{cpm}$ component in the $E G G$ is plot. absent in the respiratory grey

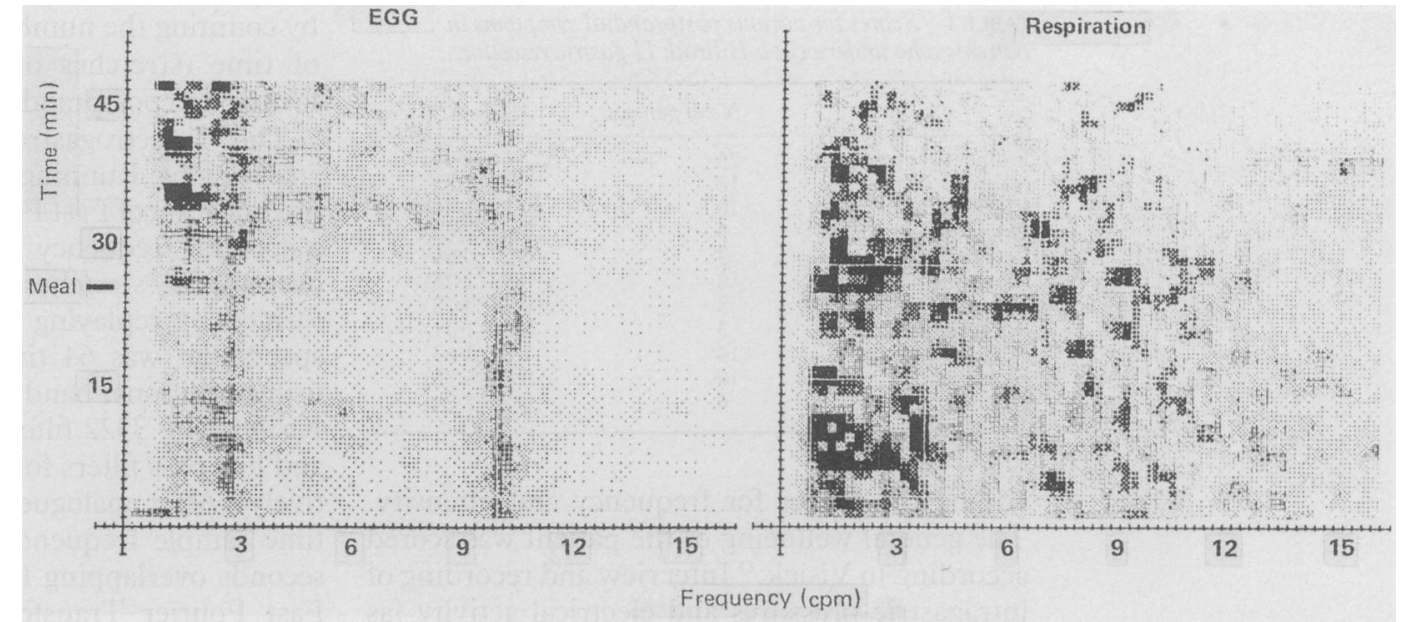

This incidence dropped to $39(33) \%$ in the first 15 minutes after the test meal, gradually increasing to $50(38) \%$ in the next 15 minutes. The mean (SD) amplitude of the contractions recorded in the fasting state was $1.3(0.9) \mathrm{kPa}$, but peak values up to $5 \mathrm{kPa}$ were recorded occasionally. The mean (SD) amplitude of the postprandial contractions was considerably smaller: $0 \cdot 7(0 \cdot 4)$ $\mathrm{kPa}$.

In 23 of the 33 patients (70\%) the electrogastrogram showed recognisable slow wave activity during at least part of the recording time, particularly after the test meal (Fig 1). Using Running Spectrum Analysis, the presence of a component at approximately $3 \mathrm{cpm}$ could be shown in 27 of 33 patients (82\%) (Fig 2). The incidence of the $3 \mathrm{cpm}$ components recorded in those patients in whom it was found, varied from 10 to $97 \%$ of the recording time. The incidence after the test meal seemed to be somewhat higher than in the fasting state $(65(26) \% v 56(30) \%)$, but this difference failed to reach statistical significance.

The power of the $3 \mathrm{cpm}$ component in the fasting state was 57 (42) arbitrary units, whereas after the test meal it was slightly higher: $67(45)$ arbitrary units. The power ratio, defined as the quotient of postprandial and fasting power, was $1.5(1 \cdot 1)$ in the Billroth II patients. The discrepancy between this figure and the figures for the mean fasting and postprandial powers is explained by the recordings in four patients in whom proper recordings could not be obtained either before or after the test meal for technical proximal jejunum of a do. The numbers refer to the 4 recordings displayed. The second lead shows electrical activity with jejunal frequency.

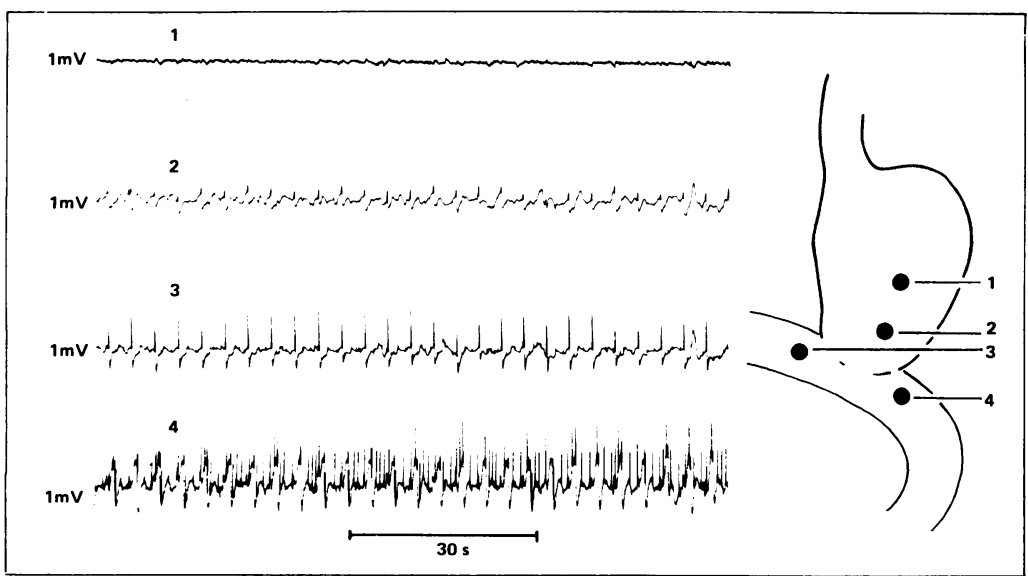

reasons. In some patients even a power decreau after the test meal was observed (Fig 2, left panel).

The frequency of the gastric component varied between subjects - in the fasting state the mean (SD) frequency was $3 \cdot 1(0 \cdot 2) \mathrm{cpm}$ (range $2 \cdot 75-3 \cdot 5)$ and postprandially the frequency was $3.0(0.2) \mathrm{cpm}$ (range 2.75-3.5). After the test meal the characteristic frequency $\operatorname{dip}^{1+16}$ was not observed in our patients.

A component of approximately $10 \mathrm{cpm}$ was present in the electrogastrographic signal in 20 patients (61\%) (Fig 2).

The mean (SD) power of this $10 \mathrm{cpm}$ band was about half that of the $3 \mathrm{cpm}$ signal - 33 (47) arbitrary units in the fasting state and 28 (47) postprandially: in several patients it disappeared completely after the test meal (Fig 2).

The mean fasting incidence of the $10 \mathrm{cpm}$ component was $49(28) \%$, the mean postprandial incidence $49(23) \%$.

The frequency of this component varied between subjects in the range of 9.5 to $12 \mathrm{cpm}$; the mean fasting frequency being $10.7(0.6)$ cpm and the postprandial frequency $10.5(0.8)$ cpm.

To investigate the nature of the $10 \mathrm{cpm}$ component in the Billroth II patients, we performed Running Spectrum Analysis on the respiratory signal in all patients in whom a recognisable $10 \mathrm{cpm}$ component was found. The frequency band at $10 \mathrm{cpm}$ could not be shown in the respiratory grey plots (Fig 2), indicating that the high frequency band in the electrogastrogram is not caused by respiration.

In the three dogs, electrical control activity with a frequency of approximately $5 \mathrm{cpm}$ was recorded from the two electrodes on the gastric remnant. In addition, a high frequency signal was recorded from the most distal of the two gastric electrodes in each of the three, particularly in the recordings made after the first three months after surgery (Fig 3). This signal was found to be present in both the fasting and postprandial states. Its frequency (approximately $18 \mathrm{cpm}$ ) was identical to that of the slow waves recorded from the jejunal electrodes.

No significant correlations were found between the characteristics of the pressure recordings and postprandial symptoms. Several significant correlations, however, were present between symptoms and characteristics of both 
TABLE II Correlations between symptom scores and electrogastrographic variables in patients who underwent a Billroth II partial gastrectomy (correlation coefficients)

\begin{tabular}{|c|c|c|c|c|}
\hline & Fullness & Nausea & Vomiting & $\begin{array}{l}\text { Early } \\
\text { dumping }\end{array}$ \\
\hline Frequency of $3 \mathrm{cpm}$ component (fasting) & $0 \cdot 37$ & $0 \cdot 42^{\star}$ & $0 \cdot 41^{\star}$ & $0 \cdot 61^{\star \star \star}$ \\
\hline Frequency of $3 \mathrm{cpm}$ component (postprandial) & $0 \cdot 41^{\star}$ & $0 \cdot 50^{\star \star}$ & $0 \cdot 58^{\star \star \star}$ & $0 \cdot 43^{\star}$ \\
\hline Power of $3 \mathrm{cpm}$ component (fasting) & $-0 \cdot 20$ & $0 \cdot 15$ & $0 \cdot 40^{\star}$ & $0 \cdot 20$ \\
\hline Frequency of $10 \mathrm{cpm}$ component (fasting) & 0.44 & $0 \cdot 60^{\star}$ & $0.51^{\star}$ & $0 \cdot 49$ \\
\hline Frequency of $10 \mathrm{cpm}$ component (postprandial) & $0 \cdot 66^{\star}$ & $0 \cdot 62^{\star \star}$ & $0 \cdot 72^{\star \star}$ & $0 \cdot 45$ \\
\hline
\end{tabular}

$\star=\mathrm{p}<0.05 ;{ }^{\star \star}=\mathrm{p}<0.02 ;{ }^{\star \star \star}=\mathrm{p}<0.01$

the low frequency $(3 \mathrm{cpm})$ and the high frequency $(10 \mathrm{cpm})$ component in the electrogastrogram. A positive correlation existed between fullness, nausea, vomiting, and early dumping and the frequency of the $3 \mathrm{cpm}$ component: patients with a lower frequency tended to have less symptoms (Table II, Fig 4). Patients with symptoms of fullness, nausea, or vomiting had slightly higher frequencies $(3 \mathrm{cpm}$ component) compared with those without these symptoms: $3 \cdot 13(0 \cdot 19) v 2.95(0 \cdot 19) \mathrm{cpm}$ in the fasting state, $3.01(0.29)$ v $2.95(0.17) \mathrm{cpm}$ postprandially. These differences, did not, however, reach statistical significance. A positive correlation existed between the fasting power of the $3 \mathrm{cpm}$ signal and vomiting. When the patients with 3 cpm activity (27 of 33) were compared with those without $3 \mathrm{cpm}$ activity (6 of 33), no significant difference in the occurrence or intensity of postprandial symptoms was found.

Scores for fullness and nausea were lower in the group of patients in whom a high frequency band of $10 \mathrm{cpm}$ was found (Fig 5) $(\mathrm{p}<0.05$, Wilcoxon test). A higher frequency within the range of 9.5-12 cpm was associated with higher scores for fullness, nausea, and vomiting (Table II). Mean fasting frequencies $(10 \mathrm{cpm}$ component) in those patients without any symptoms of fullness, nausea, or vomiting were lower than in those with symptoms: $10.29(0.53) v 10.93$ $(0.45) \mathrm{cpm}$ in the fasting period $(\mathrm{p}<0.05)$ and $9.81(0.37) v 10.82(0.75) \mathrm{cpm}$ postprandially (not significant).

No relation was found between electrogastrographic and manometry findings or symptoms and the time elapsed after surgery.

\section{Discussion}

This study has shown that in most patients who have undergone a Billroth II partial gastrectomy, phasic gastric contractions are present and can be recorded by intraluminal manometry, in particular during the fasting period. Although manometry in a wide hollow viscus is known to provide only limited information, it is clear that

Figure 4: Postprandial frequency of the 3 cycles per minute (cpm) gastric component in relation to the intensity of nausea in 25 patients who underwent a Billroth II partial gastrectomy.

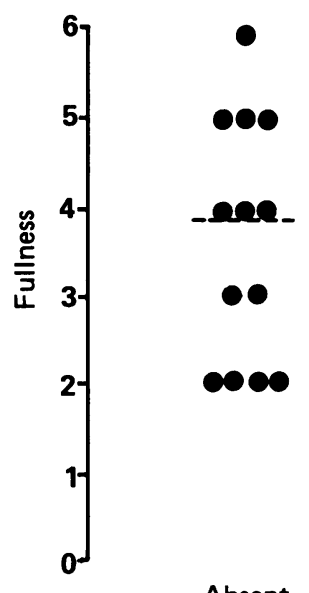

\section{$10 \mathrm{cpm}$ component}

Figure 5: Intensity of epigastric fullness in absence or presence of a $10 \mathrm{cpm}$ component. Significantly less fullness is found in patients with a $10 \mathrm{cpm}$ component in the electrogastrograph $(E G G)$; the interrupted lines indicate the median values $(p<0.05$, Wilcoxon test $)$.

phasic contractile activity, when shown manometrically, cannot be a false-positive finding.

This study also shows that in most of these patients slow waves with a similar frequency to those in the intact stomach can be recorded by means of surface recording. It seems likely, therefore, that in a Billroth II partial gastrectomy the pacemaker area is usually left intact or only partly removed. The amplitude of these slow waves, certainly postprandially, seems to be lower than in the intact stomach. ${ }^{20}$ This is not surprising since the source of the electrogastrographic signal is the smooth muscle of the distal stomach $^{18}$ and most of this is removed in Billroth II resections. Perhaps this fact is also related to the postprandial disappearance of the $3 \mathrm{cpm}$ band (and also the $10 \mathrm{cpm}$ component) in some of our patients.

As in unoperated subjects, spectral analysis of the electrogastrographic signals, in particular Running Spectrum Analysis, was found to be very useful. It provides a better insight into the characteristics of the gastric component than can be obtained by visual evaluation of the paper recording. However, the usual postprandial frequency dip followed by a rise in frequency ${ }^{17} 19$ was not seen after Billroth II resection. We suspect that our inability to detect these postprandial changes is due to the low amplitude of the electrogastrographic signal. Also, the power ratio in patients with a Billroth II gastric remnant (mean (SD) $1 \cdot 5(1 \cdot 1)$ arbitrary units), measured by means of Running Spectrum Analysis, is lower than is observed in healthy subjects in whom a power ratio of $\geq 2.0$ was shown by Geldof et al. ${ }^{17} 20$

The positive correlations which were found between the frequency of the $3 \mathrm{cpm}$ component and several symptoms are difficult to explain; a higher frequency is associated with higher scores for fullness, and nausea, for example. One cannot be sure that these relations are causal. Other factors such as myogenic, hormonal, vagal or other neural mechanisms may be responsible for both a higher gastric frequency and the occurrence of more severe symptoms. The 
relevance of these findings, therefore, is as yet uncertain.

An intriguing finding in our study was the frequent occurrence of a high frequency band of about $10 \mathrm{cpm}$ in the electrogastrogram of Billroth II patients. Such a component is rare in the intact human stomach; it is found in only $4 \%$ of the recordings in healthy volunteers. A respiratory origin was considered to be the possible cause of this signal. ${ }^{17}$

In the dog, recordings of electrical activity by means of serosal electrodes also show a component of higher frequency (about $18 \mathrm{cpm}$ ). ${ }^{317} \mathrm{By}$ simultaneous recording of duodenal electrical activity it was shown that duodenal slow waves were the origin of the $18 \mathrm{cpm}$ component.

By performing Running Spectrum Analysis of the simultaneously recorded respiratory signal we could exclude a respiratory origin for the high frequency band. Its frequency of approximately $10 \mathrm{cpm}$ made a relation with the jejunal slow wave activity likely.

Our findings in the dog lend support to this hypothesis. In all three dogs slow waves were found in the distal gastric remnant, with a frequency identical to the frequency in the jejunum just distal to the anastomosis. As bipolar electrodes were used, the slow waves recorded at the gastric leads had to be of gastric origin and could not just be electrotonically conducted from the jejunum. We concluded that, in the dog, retrograde propagation of slow wave activity occurs across the anastomosis, from the jejunum into the gastric remnant. Based on these findings, we hypothesise that in people who have undergone Billroth II resection, the presence of a frequency band at $9 \cdot 5-12 \mathrm{cpm}$ is caused by retrograde propagation of electrical activity from the jejunum. After Billroth II resection the distal stomach seems to be capable of producing not only near to normal slow wave activity $(3 \mathrm{cpm})$, but also jejunal-like activity.

Theoretically, the altered position of the jejunum in respect of the abdominal wall may be responsible for the presence of the high frequency band in the surface signal after gastrojejunostomy. The findings in dogs, however, lend support to our assumption that this band originates in the gastric remnant.

It is not known whether the distal gastric remnant is also capable of contracting at jejunal frequency. Assuming that $10 \mathrm{cpm}$ contractile activity occurs in the gastric remnant, one could understand some of the correlations present between $10 \mathrm{cpm}$ frequency and power, and symptoms: a stronger $10 \mathrm{cpm}$ contractile activity might add to the emptying capacity of the stomach. The correlation between its frequency and several symptoms, however, is more difficult to explain. Although it is clear that our knowledge of the pathophysiological mechanisms involved in symptoms so frequently encountered after gastric surgery is still limited, gastric manometry and electrogastrography may help to increase our understanding of these.

This study was supported, in part, by the Foundation of Medical Research MEDIGON, which is subsidised by the Dutch Organization for the advancement of Pure Research (ZWO).

1 El-Sharkawy TY, Morgan KG, Szurszewski JH. Intracellular electrical activity of canine and human gastric smooth muscle. F Physiol (Lond) 1978; 279: 291-307.

2 Sarna SK. Gastrointestinal electrical activity: terminology. Gastroenterology 1975; 68: 1631-5.

3 Smout AJPM. Myoelectric activity of the stomach. Gastroelectromyography and electrogastrography. Delft, The Netherlands: myography and electrogastrograph
Delft University Press, 1980.

4 Weber JJr, Kohatsu S. Pacemaker localization and electrical conduction patterns in the canine stomach. Gastroenterology 1970; 59: 717-26.

5 Hinder RA, Kelly KA. Human gastric pacesetter potential. Site of origin, spread and response to gastric transection and proximal gastric vagotomy. Am $\mathcal{F}$ Surg 1977; 133: 29-33.

6 Kelly KA, Code CF. Canine gastric pacemaker. Am $\mathcal{Y}$ Physio 1971; 217: 461-70.

7 Cox AG. Comparison of symptoms after vagotomy with gastrojejunostomy and partial gastrectomy. $\mathrm{Br} M e d \mathcal{F} 1968$; 1: $288-90$.

8 MacGregor IL, Martin P, Meyer JH. Gastric emptying of solid food in normal man and after subtotal gastrectomy and food in normal man and after subtotal gastrectomy and 72: 206-11.

9 Malmud LS, Fisher RS. Scintigraphic evaluation of disorders of the esophagus, stomach and duodenum. Med Clin North Am 1981; 65: 1291-310

10 Heading RC, Tothill P, McLoughlin GP, Shearman DJC Gastric emptying rate measurements in man. Gastroenterology 1976; 71: 45-50.

11 Smout AJPM, Akkermans LMA, Roelofs JMM, Pasma FG Oei HY, Wittebol P. Gastric emptying and postprandial symptoms after Billroth II resection. Surgery 1987; 101: 2734.

12 Nelsen ThS, Kohatsu S. Clinical electrogastrography and its relationship to gastric surgery. Am $\mathcal{F}$ Surg 1968; 116: 215-9.

13 Dudley $\mathrm{H}$, Rob Ch, Smith R. Operative surgery, fundamental international techniques: abdomen. London-Boston: Butterworths, 1977 .

14 Pasma FG. Gastric emptying after Billroth II partial gastrectomy. Dordrecht, The Netherlands: ICG Printing, 1986.

15 Visick AHA. Study of the failure after gastrectomy. Am $R$ Coll Surg 1948; 3: 266-84.

16 Abell TL, Malagelada JR. Electrogastrography: current assessment and future perspectives. Dig Dis Sci 1988; 33 982-92.

17 Geldof H. Electrogastrography: clinical applications. Dordrecht, The Netherlands: ICG Printing, 1987.

18 Smout AJPM, van der Schee EJ, Grashuis JL. What is measured in electrogastrography? Dig Dis Sci 1980; 25 : 179 87.

19 Smout AJPM, van der Schee EJ. Computer analysis of cutaneously recorded gastric electrical activity. Automedica cutaneously reco.

20 Geldof $\mathbf{H}$, van der Schee EJ, van Blankenstein M, Grashuis JL. Electrogastrographic study of gastric myoelectrical activity in patients with unexplained nausea and vomiting. Gut 1986; 27: 799-808. 